\title{
Change in morphometric and oxygen-binding properties of erythrocytes in vascular diseases patients
}

\author{
Natalia V. Gromova ${ }^{\ddagger}$, Victor V. Revin ${ }^{\ddagger}$, Nadezhda V. Revina ${ }^{\ddagger}$, Anastasiya N. Kukina ${ }^{\ddagger}$, Elvira S. Revina ${ }^{\ddagger}$ \\ Anastasiya Yu. Samonova $\ddagger$, llya N. Solomadin ${ }^{\ddagger}$, Alexander Yu. Tychkov ${ }^{\ddagger}$, Inessa Ya. Moiseeva \\ ‡ Federal state-financed academic institution of higher education, National Research Ogarev Mordovia State University, \\ Saransk, Russia \\ $\S$ Federal state-financed academic institution of higher education, Penza State University, Penza, Russia
}

Corresponding author: Natalia V. Gromova (nataly grom@mail.ru)

Received: 14 Jul 2017| Published: 17 Jul 2017

Citation: Gromova N, Revin V, Revina N, Kukina A, Revina E, Samonova A, Solomadin I, Tychkov A, Moiseeva I

(2017) Change in morphometric and oxygen-binding properties of erythrocytes in vascular diseases patients.

BioDiscovery 20: e15079. https://doi.org/10.3897/biodiscovery.20.e15079

\section{Abstract}

Now cardiovascular diseases take a leading place among the main causes of death of population. The prevalence of vascular brain lesions, which are the main causes of hypertension and atherosclerosis of cerebral arteries about 800 to 100 thousand population and it does not tend to decrease in Russia, as in most industrialized countries.

By the Raman spectroscopy and laser interference microscopy methods were studied morphometric parameters and the oxygen binding properties of erythrocytes in vascular diseases patients with the different term of vascular diseases patients before and after treatment according to the accepted scheme.

It is shown that vascular diseases together with classic development mechanism are accompanied first of all with pathological changes from the direction of erythrocytes primarily changes in morphometric characteristics such as an area, the height of the phase (optical path difference), physical height. In addition, pathological forms erythrocytes such as echinocytes, stomatocytes, spherocytes met in large amounts in blood. In patients with cardiovascular diseases observed changes conformation of haemoglobin and erythrocytes 
impaired ability to bind and release oxygen, which can lead to incomplete release of oxygen from the oxyhaemoglobin its insufficient intake in the tissue and the development of tissue hypoxia.

These data suggest that in vascular diseases the high mortality rate can associated with disorders of the blood vessels, also with change in the morphometric characteristics of erythrocytes and conformation of haematoporphyrin of haemoglobin. In turn it leads to disruption of the main functions of the erythrocytes and it reduces oxygen-transport ability of erythrocytes.

\section{Keywords}

Cardiovascular diseases, Raman spectroscopy, laser interference microscopy, erythrocytes

\section{Presenting author}

Natalia V. Gromova (nataly_grom@mail.ru)

\section{Funding program}

This work was supported by the Russian Science Foundation, Grant. No. 15-15-10025.

\section{Conflicts of interest}

The authors declare that there is no conflict of interests regarding the publication of this paper. 